\title{
COMO O MILAGRE DA LEITURA É POSSÍVEL? INVESTIGANDO PROCESSOS BIOLÓGICOS E CULTURAIS DA EMERGÊNCIA DE SENTIDOS DURANTE A LEITURA
}

\author{
Rosângela Gabriel ${ }^{*}$ \\ Universidade de Santa Cruz do Sul \\ Departamento de Letras \\ Programa de Pós-Graduação em Letras \\ Santa Cruz do Sul, RS, Brasil
}

\begin{abstract}
Resumo: Se, por um lado, a leitura é uma forma particular de usar a linguagem verbal, por outro, a fim de compreender os aspectos cognitivos envolvidos na leitura, é necessário evitar estender inadvertidamente o campo de aplicação deste objeto de estudo (MORAIS, 1996). Ao investigar a leitura, cumpre examinar que aspectos cognitivos e sociais lhe são específicos e que aspectos são compartilhados com a modalidade oral ou, ainda, com as demais linguagens, considerando processos de significação verbal e não verbal. O presente artigo distingue elementos que são intrínsecos ao aprendizado e processamento da leitura, e aspectos que são compartilhados com as demais linguagens, em especial, com a linguagem oral, buscando identificar processos conscientes e inconscientes envolvidos (DEHAENE, 2012; 2014). Uma definição de leitura e a explicitação de seu modo de processamento são necessárias para subsidiar o planejamento de políticas públicas e ações pedagógicas que estejam alicerçadas nos avanços dos estudos neurocientificos sobre linguagem, leitura e cognição.
\end{abstract}

Palavras-chave: Leitura. Aprendizagem. Processamento. Processo consciente e inconsciente. Educação.

1 INTRODUÇÃO1

Quando falamos sobre leitura no dia a dia, nossa atenção em geral está voltada para o assunto do texto, para o autor, ou para o lugar em que o texto foi publicado, qual a perspectiva adotada pelo autor... Poucas vezes, nossa atenção volta-se para a atividade leitora per se ou para o próprio fenômeno denominado "leitura". No livro "Fogo Pálido", de Vladimir Nabokov², a personagem Dr. Charles Kimbote declara, a certa altura:

\begin{abstract}
Nós estamos absurdamente acostumados ao milagre de que alguns poucos sinais escritos sejam capazes de conter imagens imortais, involuções do pensamento, novos mundos com pessoas vivas, falando, chorando, rindo. Tomamos isso como dado tão simplesmente que, em
\end{abstract}

\footnotetext{
* Docente do Programa de Pós-Graduação em Letras e do Departamento de Letras da UNISC Universidade de Santa Cruz do Sul. Bolsista de Produtividade em Pesquisa CNPq. E-mail: rgabriel@unisc.br

${ }^{1}$ Uma primeira versão do presente artigo foi apresentada durante o V SIMELP - Simpósio Mundial de Estudos de Língua Portuguesa, que ocorreu em Lecce, Itália, em outubro de 2015.

${ }^{2}$ Disponível em $<$ https://www.google.be/\#q=pale+fire+pdf $>$. Acesso em: 5 jan. 2016

GABRIEL, Rosângela. Como o milagre da leitura é possível? Investigando processos biológicos e culturais da emergência de sentidos durante a leitura. Linguagem em (Dis)curso - LemD, Tubarão, SC, v. 16, n. 3, p. 603 616, set./dez. 2016.
} 
certo sentido, pelo simples ato de rotineira aceitação ignorante, desmerecemos o trabalho milenar, a história da gradual elaboração da descrição e construção poética, do homem que habitava árvores a Browning, do homem das cavernas a Keats. E se acordássemos um dia, todos nós, e nos descobríssemos incapazes de ler? Eu gostaria que vocês se maravilhassem não apenas com o que leem, mas também com o milagre de que tal possa ser lido ${ }^{3}$.

A pergunta lançada no trecho acima pode nos remeter a outra obra literária, Ensaio sobre a cegueira, de José Saramago (1995), em que as personagens não só descobrem-se subitamente incapazes de ler, mas também de ver. As situações ficcionais propostas por Nabokov e Saramago ajudam-nos a desnaturalizar o fenômeno da leitura, para que possamos refletir sobre ele. A leitura faz parte de nossas vidas de forma tão onipresente e "natural", que muitas vezes esquecemos que ela é um artefato cultural, uma criação da genialidade humana, da capacidade que temos de criar cultura e aprender com nossos coespecíficos (VYGOTSKY, 1998; TOMASELLO, 1999). O trabalho milenar que deu origem à tecnologia mais revolucionária já inventada pela humanidade, começando com desenhos esculpidos no interior de cavernas até o registro "nas nuvens" da era digital, procura ser reconstruído por estudos como os desenvolvidos pela História da Leitura (ABREU, 2000; CAVALLO; CHARTIER, 1999; ZILBERMAN, 1989; 2001). Noutra perspectiva, a Linguística do Texto procura compreender as micro e macrosestruturas presentes no texto que engendram a coesão e a coerência, possibilitando que a comunicação escrita alcance desempenho semelhante à oral, ou superior em determinados contextos, se considerarmos a possibilidade de permanência do registro escrito de um lado, e a maior efemeridade do discurso oral por outro (KOCH; FÁVERO, 1985; KOCH; TRAVAGLIA, 1989; KOCH; ELIAS, 2006), ou ainda, se pensarmos na literatura como arte, cuja matéria prima é a palavra escrita.

O estranhamento diante do milagre da leitura, ao qual nos conclama Nabokov, pode nos levar a outras perspectivas, tais como a das neurociências. O que nosso corpo (e nosso cérebro) faz quando lemos (DEHAENE, 2012; SCHOTTER; RAYNER, 2015)? O que o corpo (e o cérebro) de quem não lê (por exemplo, uma criança antes dos 5 anos ou um adulto não letrado) faz diante de um texto escrito (PEGADO et al., 2014; DEHAENE et al., 2015)? O que faziam os neurônios que processam a leitura em um leitor proficiente antes da aprendizagem dessa habilidade (DEHAENE; COHEN, 2007; DEHAENE et al., 2010)?

A leitura pode ainda ser abordada a partir de uma perspectiva educacional, econômica e social: a leitura se tornou uma ferramenta tão fundamental para a vida em sociedade que o desempenho em leitura dos cidadãos interessa não só ao indivíduo ou à comunidade escolar, mas também aos governos, e a organizações como a OECD (Organização para a Cooperação e Desenvolvimento Econômico, em inglês, Organisation for Economic Co-operation and Development), cujo objetivo é promover políticas para incrementar o bem-estar social e econômico mundial e que é responsável pelo PISA (Programa para Avaliação Internacional de Estudantes, em inglês, Programme for International Student Assessment). Se a leitura é uma habilidade tão fundamental, podendo ser considerada um direito humano em sociedades democráticas (MORAIS,

\footnotetext{
${ }^{3}$ As traduções apresentadas ao longo do artigo são de responsabilidade da autora.
} 
2016), como assegurar que todos tenham acesso a esse bem e possam aprender a ler, desenvolvendo a habilidade leitora?

As diversas perspectivas brevemente referidas nesta introdução nos dão uma indicação da complexidade e importância do tema, tanto do ponto de vista do indivíduo quanto da sociedade. Neste artigo, procuramos abordar a leitura a partir de um ponto de vista interdisciplinar, congregando conhecimentos das Neurociências, da Linguística, da Psicologia Cognitiva e da Educação. Procuramos refletir sobre dois aspectos que parecem estar no cerne dos maus resultados apresentados pelas políticas públicas e pelas orientações pedagógicas voltadas à melhoria dos níveis de leitura dos estudantes brasileiros. O primeiro aspecto, abordado na seção que segue esta introdução, diz respeito aos processos conscientes e inconscientes envolvidos na leitura. $\mathrm{O}$ segundo aspecto, abordado na terceira seção, refere-se à complexa relação entre a linguagem oral e a escrita, bem como aos componentes da compreensão leitora. Na última seção, voltamos nossa atenção ao contexto brasileiro, buscando sintetizar as contribuições que uma perspectiva amparada na ciência da leitura pode trazer para o planejamento de políticas públicas e a intervenção pedagógica.

\section{PROCESSOS CONSCIENTES E INCONSCIENTES ENVOLVIDOS NA LEITURA}

Uma metáfora muitas vezes referida quando se trata de processos cognitivos conscientes e inconscientes é a do iceberg. Assim como a ponta visível do iceberg, o processamento cognitivo consciente é parte, e não todo o iceberg. Quando pensamos em leitura, novamente a metáfora do iceberg nos ajuda a compreender como a um só tempo estamos conscientes e inconscientes dos processos envolvidos. Além disso, a automatização faz com que processos dos quais temos consciência num determinado estágio de aquisição possam tornar-se inconscientes noutro estágio, acarretando inclusive incremento no desempenho. Pensemos, por exemplo, em como aprendemos a dirigir um carro (a série de ações coordenadas que precisam ser efetuadas e o esforço consciente de pensar em cada uma delas) e em como dirigimos após alguns anos de experiência: acelerar, debrear, frear passam a ser ações automatizadas, inconscientes, enquanto a atenção consciente fica liberada para monitorar as condições do trânsito ou planejar o caminho a ser percorrido. No processo de aprendizagem da leitura, a automatização desempenha papel fundamental, como veremos ao longo deste artigo.

Dehaene (2014) explora a relação entre processos cognitivos conscientes e inconscientes. De acordo com o autor, nunca vemos uma imagem como nossa retina vê. Ao contrário de um conjunto distorcido de pixels, permeado por vasos sanguíneos, com um ponto cego central, o que vemos é uma imagem tridimensional corrigida e reinterpretada a partir de nossas experiências prévias. Esse processo de correção e reinterpretação é inconsciente, assim como o processo de agrupamento das unidades significativas (chunks) na memória de trabalho (para uma revisão, ver GABRIEL et al., 2016). Nossa capacidade de reconhecer palavras escritas deriva da capacidade inconsciente de aprendizagem estatística: ao longo da vida, um leitor adulto vê milhões de palavras, e seu córtex visual contém neurônios preparados para identificar sequências frequentes. Durante o processamento de frases simples, a mente está consciente do tópico, 
e a maioria das palavras isoladas (sem mencionar fonemas e morfemas) não atinge o limiar de consciência. Já durante o processamento de frases complexas, ambíguas ou metafóricas, a mente inconsciente ativa vários possíveis significados, ao passo que a mente consciente escolhe qual desses significados é mais apropriado ao contexto. Nas palavras de Dehaene (2014, p. 66): "A mente inconsciente propõe enquanto a mente consciente seleciona" ${ }^{4}$.

A metáfora do iceberg é útil, ainda, quando pensamos no ensino e aprendizagem da leitura: assim como a ponta visível do iceberg pode levar o comandante do navio a subestimar o perigo iminente, como na famosa tragédia do Titanic, a parte observável da leitura pode levar o professor (ou os responsáveis pelo estabelecimento de políticas públicas direcionadas ao desenvolvimento da leitura) a subestimar a importância dos processos inconscientes envolvidos na leitura realizada pelo leitor hábil, os quais, no entanto, precisam ser aprendidos, de forma explícita e consciente pelo leitor iniciante.

Um exemplo de como a pedagogia da leitura pode ser traída pela ilusão do iceberg é o processo de transformação dos sinais gráficos em linguagem oral. Ler implica um sistema complexo de transformação dos sinais de entrada - o sinal gráfico, em representações de sua pronúncia e de seu significado. De acordo com Morais (2013, p. 11), ler é "traduzir" o que está escrito, traduzir aquilo que o texto escrito representa, quer dizer, a fala. Nos sistemas de escrita alfabética, esse processo de tradução implica que o leitor iniciante decodifique os grafemas (letras ou conjunto de letras ${ }^{5}$ ) em fonemas (unidades fonológicas da língua que distinguem palavras entre si).

No Glossário de "Termos de Alfabetização, Leitura e Escrita para Educadores", do Ceale/Ufmg, Coscarelli (2016) define decodificação como o "processo no qual o leitor transforma as retas e curvas que compõem as letras em sons oralizados ou numa imagem mental do som". Essa operação poderia ser considerada um processo simples de associação (GOUGH; HILLINGER, 1980), se as letras representassem sempre o mesmo som, mas não é o que acontece. As línguas variam quanto à consistência com que a fonologia é representada pela ortografia - ou seja, o grau de previsibilidade da pronúncia de uma determinada letra ou conjunto de letras -, com línguas em que a relação grafemafonema é mais transparente, num extremo, como o finlandês, até línguas altamente imprevisíveis, como o inglês (ZIEGLER; GOSWAMI, 2005; 2006). Coscarelli (2016) propõe o exemplo da palavra "banana", em que temos três ocorrências da letra A, mas em cada uma delas essa letra representa um som diferente (em algumas variantes do português os sons são: [a], [ã], /Ә/, respectivamente, e em outras /ã/, /'ã/,/Ә/), mas poderíamos também pensar no caso emblemático da letra " $x$ ", que representa diferentes fonemas em "xícara", "táxi", "excesso" e "exame", sendo que esses mesmos fonemas podem ser escritos com outros grafemas, como no caso de "churrasco", "acesso" e "azeite".

\footnotetext{
${ }^{4}$ The unconscious mind proposes while the conscious mind selects.

${ }^{5} \mathrm{Um}$ grafema é uma letra ou um conjunto de letras que corresponde a um fonema. Por exemplo, o grafema "p" corresponde ao fonema /p/, ao passo que o grafema "ss" em "pássaro" corresponde ao fonema $/ \mathrm{s} /$.

${ }^{6}$ Não nos ocorre nenhum exemplo em português em que os fonemas /ks/, de táxi, sejam escritos com outro grafema que não o " $\mathrm{x}$ ", mas talvez o leitor aprendiz seja tentado a grafar esses fonemas com dois grafemas, como em "tacsi" ou "taksi", por exemplo.
} 
A decodificação pressupõe que o leitor aprendiz tenha compreendido o princípio alfabético, segundo o qual os grafemas representam os fonemas da língua. Para um leitor alfabetizado, ou seja, que saiba ler em uma escrita alfabética, esse princípio parece bastante óbvio. No entanto, se considerarmos outros sistemas de escrita, por exemplo, o chinês e o japonês, em que os grafemas representam palavras, conceitos ou sílabas, veremos que esse princípio não é óbvio e precisa ser explicitado às crianças. Esse talvez seja um dos pontos a ser enfatizado e repetido como um mantra, quando se trata de ensino de leitura: o que parece óbvio para o leitor proficiente (processado, em geral, de forma inconsciente) não o é necessariamente para o aprendiz!

A decodificação, ainda que imprescindível, é apenas o primeiro passo a ser dado no processo de transformação dos sinais gráficos em linguagem oral. À medida que o leitor ganha familiaridade com a forma escrita das palavras, o processo de decodificação vai dando lugar à conversão ortográfica (FRITH, 1985), em que unidades ortográficas correspondem idealmente a morfemas ou palavras. A leitura proficiente implica fluência (leitura rápida, não truncada) e essa só é atingida por meio da automatização (ou seja, transformação de um processo consciente em inconsciente) da decodificação e gradual armazenamento das representações de palavras em sua forma ortográfica na memória de longo prazo. Embora seja um processo inconsciente para o leitor proficiente, este pode lançar mão da decodificação consciente quando necessário, por exemplo, diante de palavras novas, de difícil pronúncia ou potencialmente conflitantes (como no caso de palavras parônimas, como delatar/dilatar/deletar).

A prática frequente da leitura e da escritura, seja com propósitos pragmáticos (utilitários), divertimento, ampliação do conhecimento ou fruição estética (literária), possibilita o desenvolvimento da literacia (tradução do termo inglês, literacy). Segundo Morais (2016), a literacia não se confunde com a alfabetização por duas razões: primeiro, porque alguém pode saber ler em árabe, japonês ou chinês sem ter sido alfabetizado, já que essas línguas não utilizam o alfabeto. Segundo, porque a literacia pressupõe o uso fluente da leitura e da escrita, não como um fim, mas como um meio, uma ferramenta. Como dissemos no início deste artigo, o leitor fluente, em geral, não pensa em como lê, mas sim no que lê, portanto sua atenção consciente está voltada para a construção de sentidos durante a leitura, o que se torna possível exatamente porque a transformação dos sinais gráficos em linguagem (oral ou mental, como na leitura silenciosa) já está automatizada. Nesse sentido, a literacia poderia ser tomada como sinônimo de letramento, mas esse termo ganhou no Brasil uma conotação bastante particular, que parece negligenciar os aspectos específicos da leitura (desenvolvimento da consciência fonológica, identificação de letras e padrões ortográficos, conhecimento do vocabulário e de expressões mais frequentes na língua escrita, reflexão sobre as micro e macroestruturas características de diferentes gêneros textuais), enfatizando seu papel enquanto prática social, como se houvesse um conflito inerente a esses dois aspectos (MORAIS, 2003; SOARES, 2004). Na perspectiva que adotamos, a alfabetização e a literacia qualificadas são imprescindíveis para o uso da leitura e da escrita enquanto prática social, e precisam ser abordadas de forma objetiva e consciente nos programas que se propõem a incrementar a alfabetização e compreensão leitora. Voltaremos a esse assunto na sequência deste artigo. 
À palavra 'leitura' são atribuídos muitos significados, dependendo do contexto em que é empregada. De um ponto de vista cognitivo e também educacional, a definição do que entendemos por leitura é determinante das práticas consequentes, tanto do ponto de vista da investigação quanto da intervenção pedagógica. Para Morais (1996, p. 111), para compreender o que é leitura, temos que evitar estender nosso objeto de estudo, a fim de apreender o que ele tem de específico, de intrinsecamente relevante. Portanto, para entender como é possível ler, nosso primeiro desafio é dizer o que há de específico na leitura.

A leitura pressupõe a escrita, que se desenvolveu inicialmente como um sistema de representação da linguagem falada. Entretanto, ainda que a escrita tenha sido inicialmente uma tentativa de escrever a fala, seu uso ao longo dos séculos contribuiu para a constituição de uma nova modalidade de comunicação, cujas convenções são compartilhadas culturalmente, e que precisam ser aprendidas pelos novos membros da comunidade. É importante lembrar que a escrita é uma invenção cultural relativamente recente (em torno de 5.000 anos), constituindo-se em uma forma particular de uso da linguagem. Por isso, é previsível que linguagem oral e escrita compartilhem uma série de características, mas, o que as distingue? O Quadro 1 a seguir ilustra dez critérios de comparação.

\section{Quadro 1 - Dez critérios ilustrativos da relação entre linguagem verbal oral e escrita}

\begin{tabular}{|c|c|c|}
\hline Linguagem verbal & Oral & Escrita \\
\hline 1. Aprendizagem & $\operatorname{sim}$ & $\operatorname{sim}$ \\
\hline 2. Compreensão & $\operatorname{sim}$ & $\operatorname{sim}$ \\
\hline 3. Interpretação & $\operatorname{sim}$ & $\operatorname{sim}$ \\
\hline $\begin{array}{l}\text { 4. Linguagem }+ \text { literal versus } \\
\text { ling. }+ \text { metafórica }\end{array}$ & $\operatorname{sim}$ & $\operatorname{sim}$ \\
\hline 5. Interação & falante - discurso - ouvinte & [autor] - texto - leitor \\
\hline 6. Variação linguística & + variação; + coloquial & + estável; + formal \\
\hline 7. Léxico & + repetição; - diversidade & + diversidade $;+$ densidade \\
\hline 8. Sintaxe & $\begin{array}{l}\text { + orações curtas; } \\
\text { + ordem direta; }\end{array}$ & $\begin{array}{l}\text { + orações subordinadas; + voz } \\
\text { passiva; + ordem inversa }\end{array}$ \\
\hline 9. Conhecimento prévio & Temas de domínio comum & Maior abrangência temática \\
\hline $\begin{array}{l}\text { 10. Tradução dos sinais } \\
\text { visuais em linguagem }\end{array}$ & NÃO & SIM \\
\hline
\end{tabular}


Ao compararmos situações de uso da linguagem verbal oral e escrita, podemos concluir que ambas podem ter como objetivo a aprendizagem, a compreensão e a interpretação (KINTSCH, 1998; DASCAL, 2006; GABRIEL et al., 2012).

Ambas as modalidades apresentam expressões mais literais ou mais metafóricas, não sendo a linguagem figurada uma prerrogativa literária (LAKOFF; JOHNSON, 2002; GIBBS, 1994; 2002; GABRIEL et al., 2011).

Ambas as modalidades pressupõem interação, ainda que atores e contextos se distingam: nas situações de comunicação oral, as informações contextuais tendem a ser mais compartilhadas, ao passo que na escrita muitas informações não são dadas e precisam ser inferidas, o que pressupõe conhecimentos compartilhados, sendo que parte desses conhecimentos têm origem nos próprios interlocutores: falante-ouvinte, autorleitor (FLÔRES; GABRIEL, 2012).

Ambas as modalidades apresentam variação linguística, com a linguagem escrita tendendo à maior estabilidade e formalidade, em oposição à maior variação e informalidade da linguagem oral (KATO, 1986; MARCUSCHI, 2007).

Ambas as modalidades amparam-se no conhecimento lexical, sendo que a linguagem escrita apresenta maior densidade e diversidade lexical quando comparada à linguagem oral (NAGY; ANDERSON, 1984; CUNNINGHAM, 2005; JOHANSSON, 2008).

Ambas as modalidades compartilham características comuns da sintaxe da língua, sendo que a linguagem escrita se caracteriza por construções sintáticas mais longas, uso de ordem inversa, estruturas subordinadas e maior uso de voz passiva (MACWHINNEY; BATES, 1989; BATES et al., 1995; GABRIEL, 2001).

Ambas as modalidades amparam-se no conhecimento prévio, porém o contexto das interlocuções orais tende a ser mais compartilhado e familiar (família, escola, trabalho, comércio, etc.), proporcionando informações multimodais que se somam e complementam as informações verbais (MORATO; BENTES, 2013). Assim, os interlocutores podem apoiar-se em informações de diferentes origens para a atribuição de sentidos. Durante a leitura, por sua vez, o contexto é menos óbvio, englobando, a priori, qualquer área do conhecimento humano. Ainda que o autor tenha em mente um possível leitor, com um conjunto de conhecimentos, evidenciados no que é dito e no que não é dito, o texto escrito se emancipa do autor, ganhando públicos diversos, em períodos históricos diversos. Por isso, a compreensão em leitura muitas vezes é prejudicada por lacunas de informações contextuais imprescindíveis.

Observemos a proposta de continuum explicitada pelos sinais $+\mathrm{e}-$ presentes no Quadro 1: uma análise cuidadosa de cada critério nos revela não dicotomias, mas sim gradações. Não é necessário dizer que cada um desses critérios constitui uma área de pesquisa per se, e que os procedimentos utilizados na compreensão da linguagem oral e escrita não são exatamente os mesmos, como, por exemplo, o processo de referenciação, a interpretação de elementos dêiticos, as pistas prosódicas ou a possibilidade de releitura ou de interpelação do interlocutor, nas respectivas modalidades. Entretanto, essa gama de nuanças mais ou menos sutis não será discutida em profundidade neste artigo por uma questão de foco e de espaço. 
Os nove primeiros critérios elencados no Quadro 1, sintetizados nos parágrafos anteriores, apontam compartilhamentos entre linguagem oral e escrita, bem como diferentes gradações e intensidades. O último critério, no entanto, distingue-se dos demais. Para melhor entendê-lo, imaginemos a situação proposta por Nabokov: E se um dia acordássemos, todos nós, e nos descobríssemos incapazes de ler? E se, como em "Ensaio sobre a cegueira", de José Saramago (1995), um de nós mantivesse a capacidade de ver/ler e lesse para os demais: Quem compreenderia o texto lido? Quem estaria lendo, literalmente?

A transformação de sinais gráficos, visuais, em sons da linguagem oral, que abrange a tradução nos sistemas de escrita alfabéticos de grafemas em fonemas, e, no leitor proficiente, de padrões ortográficos em linguagem oral, está presente apenas na linguagem escrita. Ainda que possamos compreender e aprender a partir da leitura feita por outrem, só lemos, em sentido estrito, quando somos autores dessa transformação.

O conceito de leitura, as dificuldades na aprendizagem da leitura, e a necessidade de definir com precisão o objeto de estudo que temos em mente quando tratamos de leitura, vem sendo discutida por vários autores, com propostas que merecem nossa atenção.

Hoover e Gough (1990) propuseram uma visão "simples" da leitura (The Simple View of Reading), segundo a qual a leitura hábil pode ser caracterizada como o produto das habilidades de decodificação e compreensão linguística, sendo esses dois elementos de igual importância: se há decodificação, mas não há compreensão linguística, não há leitura; por outro lado, se há compreensão linguística, mas não há decodificação, não há leitura. A visão "simples" da leitura não pressupõe que a decodificação nem a compreensão sejam simples, quer na modalidade oral ou escrita, mas sim que esses dois componentes, independentes entre si, constituem a leitura hábil em proporções equivalentes.

Kamhi (2007) propõe uma visão restrita da leitura (Narrow View of Reading), em que o conceito de leitura seria limitado à leitura de palavras (reconhecimento de palavras e decodificação) e a compreensão (reflexão, raciocínio, interpretação), ou melhor, as dificuldades de compreensão não seriam questões de leitura, mas sim de carência de conhecimento em domínios específicos. Para o autor, os Estados Unidos e outros países estariam evidenciando, mais do que uma crise de leitura, uma crise de falta de conhecimentos. Kamhi (2009a; 2009b), a partir das críticas à sua proposta, reavaliou sua posição, sem, no entanto, deixar de enfatizar que a falta de clareza sobre que aspecto está sendo medido nos testes de avaliação da compreensão leitora (se o reconhecimento de palavras, a compreensão leitora em domínios gerais ou o conhecimento de um assunto específico), obscurece os resultados e dificulta a tomada de atitudes políticas e pedagógicas que possam trazer contribuições efetivas para minimizar a crise.

Em um estudo longitudinal, investigando a leitura inicial e as habilidades linguísticas de crianças com dificuldades de compreensão leitora, dos 5 aos 8 anos de idade, Nation et al. (2010) constataram que fragilidades em aspectos da linguagem oral foram detectados em crianças que posteriormente apresentaram dificuldades de compreensão leitora. Esse resultado é extremamente relevante, se considerarmos que, até a sua publicação, não estava claro se as dificuldades de compreensão da linguagem oral 
eram uma consequência do baixo aproveitamento que os leitores pobres ${ }^{7}$ fazem da atividade leitora (ampliação de vocabulário e dos conhecimentos relacionados, por exemplo), ou se essas dificuldades já estavam presentes antes da aprendizagem da leitura, tendendo à ampliação da lacuna entre bons leitores e leitores com dificuldades de compreensão. Segundo os autores, as variações na linguagem oral nos anos pré-escolares são um bom preditor da compreensão leitora no segundo ano escolar. Além disso, o estudo mostrou que os leitores com dificuldades de compreensão apresentaram menor consciência fonológica nos anos iniciais e também baixa competência no processamento de sentenças e na compreensão de frases faladas, sugerindo a intervenção precoce junto a crianças com baixo desempenho na linguagem oral, a fim de evitar baixo desempenho futuro também na linguagem escrita.

Nesse mesmo sentido, Snowling e Hulme (2012) advogam a presença de dois componentes independentes no processo de compreensão em leitura nos primeiros anos de aprendizagem, o que gera a necessidade de considerar pelo menos duas categorias de leitores deficientes: leitores cujas dificuldades em leitura sejam decorrentes da decodificação ineficiente (lenta e/ou não acurada); e leitores cujas dificuldades sejam decorrentes do conhecimento insuficiente da linguagem oral (vocabulário, estruturas gramaticais, entre outros aspectos que desempenham papel relevante na compreensão).

Seidenberg (2013) retoma a distinção proposta por Snowling e Hulme (2012) ao considerar a realidade americana, em especial a das crianças oriundas de famílias hispânicas aprendendo a ler em inglês e a de usuários de variantes dialetais como a dos afrodescendentes, que apresentam domínio insuficiente da língua inglesa utilizada nos textos escritos. Se considerarmos a realidade brasileira, podemos traçar uma analogia com relação às variantes dialetais da linguagem oral usadas por grupos cultural e socioeconomicamente desfavorecidos, que se distanciam daquelas usadas nos textos escritos, representando assim um obstáculo à compreensão.

Os estudos e reflexões apresentados nesta seção reiteram a intrínseca relação entre linguagem oral e escrita, e ao mesmo tempo as distinguem. A leitura é uma criação cultural, como referido no início deste artigo, não disponível a todos: há povos ágrafos, há adultos analfabetos em sociedades letradas e há crianças que não compreendem o que leem, mesmo depois de anos de escolarização. Se, de um lado, aprendemos a linguagem oral a partir da interação com outros seres humanos, adquirindo inicialmente a variante linguística utilizada pelo grupo familiar, a aprendizagem da linguagem escrita requer, além da exposição a textos escritos, instrução explícita, consciente e sistemática nos vários componentes da linguagem (fonológico, semântico, sintático, pragmático), como ilustrado no Quadro 1. Ao mesmo tempo, um diagnóstico preciso do tipo de dificuldade apresentada pelos leitores pouco fluentes é altamente desejável, para viabilizar o planejamento de intervenções qualificadas, que atendam às necessidades das crianças em risco de se tornarem leitores pobres ou que já apresentem dificuldades de leitura cristalizadas.

\footnotetext{
${ }^{7}$ A literatura especializada na área de leitura cunhou o termo poor readers para denominar os leitores com dificuldades de leitura. $\mathrm{Na}$ falta de um termo sucinto em português, adotamos aqui a tradução literal da expressão, leitores pobres, sem que essa faça referência ao estatuto socioeconômico do leitor, mas sim ao seu desempenho em leitura.
} 
E se acordássemos um dia, todos nós, e nos descobríssemos capazes de ler? Esta questão, uma antítese à pergunta de Nabokov, sintetiza o desejo de tantos que vêm trabalhando para a universalização do direito de todos à alfabetização e à literacia. Para que esse objetivo seja alcançado, muitos esforços vêm sendo empreendidos, em vários países. É verdade que o século XX testemunhou reduções dramáticas do analfabetismo adulto e a consolidação do direito ao ingresso e permanência na escola. No contexto brasileiro, o ensino obrigatório e gratuito, que até 1971 restringia-se a quatro anos (curso primário), passou a oito anos no período de 1971 a 2009, e a nove anos a partir de 2010, com início do Ensino Fundamental aos 6 anos de idade. Por outro lado, a profusão de dados sobre a qualidade da educação promovida pelo sistema de ensino brasileiro mostra que há muito a avançar. De acordo com os dados do INEP/OCDE (2012; 2013), 49,2\% dos estudantes brasileiros de 15 anos de idade encontram-se no nível 2 de leitura (em uma escala de 1 a 6), sendo capazes de reconhecer a ideia principal do texto, entender relações de partes delimitadas, fazer inferências elementares em tópico familiar, e não muito mais. Apenas $0,5 \%$ dos estudantes brasileiros dessa faixa etária encontra-se no nível 5, estando aptos a localizar e organizar informações profundamente entranhadas no texto, cuja interpretação e reflexão exijam compreensão detalhada. Outro dado a ter em mente é que os baixos resultados nas avaliações em leitura concentram-se nos grupos sociais menos favorecidos, o que indica a necessidade de intervenção do poder equalizador do Estado, a fim de garantir educação de qualidade para todos.

Em 2012, o governo brasileiro lançou um programa promissor. O Pacto Nacional pela Alfabetização na Idade Certa - Pnaic prevê a ação conjunta dos estados, municípios e federação no sentido de proporcionar a formação continuada de professores alfabetizadores e orientadores de estudo; disponibilizar material didático, obras literárias e de apoio pedagógico, jogos e tecnologias educacionais; realizar avaliações sistemáticas; e fazer a gestão, mobilização e controle social do Pacto.

Ainda que a iniciativa seja louvável, o estudo desenvolvido por Lopes (2015) aponta lacunas importantes nessa iniciativa, que podem comprometer seus resultados. A partir da análise dos Cadernos de Formação do Pnaic e de entrevistas com professores do ciclo de alfabetização (primeiro ao terceiro ano do Ensino Fundamental), a pesquisa constatou que a formação proporcionada pelo Pacto não aborda uma das questões mais pertinentes no processo de alfabetização, a instrução fônica e explícita dos fonemas e grafemas, a sistematização de atividades de consciência fonológica, pré-requisito para a realização da decodificação das palavras, que, ao mesmo tempo, contribui para fluência leitora e o incremento da compreensão.

Um dos pontos positivos apresentados pelos entrevistados foi a distribuição de livros de literatura infantil e jogos para as escolas, contribuindo para a exposição das crianças a materiais de leitura interessantes, em geral, lidos pela professora, numa abordagem pedagógica cunhada como "leitura deleite". No entanto, pouca ou nenhuma ênfase foi dada ao modo de detectar e amparar precocemente crianças com dificuldades na aprendizagem da leitura, ou que possam vir a apresentar dificuldades. Não há dúvida de que a leitura deleite é bem-vinda e desejável na escola, mas para que todas as crianças 
possam usufruir desse prazer também de forma autônoma, e não apenas ao ouvir a leitura feita por outrem, é necessário desenvolver as competências necessárias para a decodificação rápida e fluente, a ampliação do vocabulário e das construções linguísticas. Além disso, a leitura pode ter outros objetivos, tão nobres quanto o prazer: a busca de informação, de conhecimento, e de desenvolvimento do raciocínio.

A falta de reflexão sobre os aspectos conscientes e inconscientes da leitura e sobre a complexa relação entre as modalidades oral e escrita da linguagem fica evidente na fala dos professores alfabetizadores, que se dizem preocupados com os alunos que apresentam dificuldades na aprendizagem da leitura e compreensão textual, mas ao mesmo tempo sentem-se desamparados, sem saber de que maneira intervir no processo. Essa situação é especialmente dramática no terceiro ano do ciclo, que recebe crianças com 8 anos, muitas das quais ainda não automatizaram a decodificação fluente, comprometendo, assim, o avanço no processo de aprendizagem por meio da leitura e da escrita. Parece-nos bastante injusto e pouco eficaz postergar a avaliação das competências desenvolvidas ao longo do ciclo para o terceiro ano, quando na verdade o diagnóstico precoce das dificuldades (reconhecimento de palavras, pouco domínio das variantes mais formais da língua, lacunas em conhecimentos específicos) poderia instrumentalizar professores e comunidade escolar para a intervenção precoce concomitantemente ao longo dos três anos do ciclo, deslocando o foco da atenção da questão de reprovar ou não a criança para a questão mais fulcral: que tipo de intervenção pedagógica (ou clínica, quando for o caso) pode ser oferecida, para que todos sejam capazes de ler? Ou ainda, parafraseando o slogan do programa americano, para que nenhuma criança fique para trás ${ }^{8}$ ?

\section{AGRADECIMENTOS}

A autora agradece à equipe da Unité de Recherche en Neurosciences Cognitives (UNESCOG), Center for Research in Cognition\&Neurosciences (CRCN), Université Libre de Bruxelles (ULB), Bélgica, pelo acolhimento e pela infraestrutura disponibilizada durante o estágio de pesquisa (2015-2016). A preparação deste artigo contou com o apoio da Capes (Processo BEX 5192/14-5), da Fapergs (Edital Pesquisador Gaúcho 02/2014) e da Universidade de Santa Cruz do Sul (Res. 083/2013).

\section{REFERÊNCIAS}

ABREU, M. (Org.). Leitura, história e história da leitura. São Paulo: FAPESP; Campinas: ALB; Mercado das Letras, 2000.

BATES, E.; HARRIS, C.; MARCHMAN, V.; WULFECT, B.; KRITCHEVSKY, M. Production of complex syntax in normal ageing and Alzheimer's disease. Language and Cognitive Processes, v. 10, $\mathrm{n}$. 5, p. 487-539, 1995.

BRASIL. Manual do Pacto pela Alfabetização na Idade Certa. Disponível em: $<$ http://pacto.mec.gov.br/opacto>. Acesso em: 5 out. 2015.

CAVAllO, G.; CHARTIER, R. (Org.). História da leitura no mundo ocidental. Trad. de Cláudia

\footnotetext{
${ }^{8}$ Alusão ao programa instituído pelo governo americano No child left behind (USA, 2001).
} 
Cavalcanti, Fulvia M. L. Moretto, Guacira Marcondes Machado e José Antônio de Macedo Soares. São Paulo: Ática, 1999. 2 v.

COSCARELLI, C. V. Glossário de Termos de Alfabetização, Leitura e Escrita para Educadores. Ceale/Ufmg. Disponível em:

$<$ http://ceale.fae.ufmg.br/app/webroot/glossarioceale/verbetes/decodificacao>. Acesso em: 7 jan. 2016.

CUNNINGHAM, A. E. Vocabulary growth through independent reading and reading aloud to children. In: HIEBERT, E. H.; KAMIL, M. (Ed.). Bringing scientific research to practice: vocabulary. Mahwah, N.J.: Erlbaum, 2005. p. 45-68.

DASCAL, M. Interpretação e compreensão. São Leopoldo: Unisinos, 2006. 720 p.

DEHAENE, S.; COHEN, L. Cultural recycling of cortical maps. Neuron, n. 56, p. 384-398, 2007.

DEHAENE, S.; PEGADO, F.; BRAGA, L. W.; VENTURA, P.; NUNES FILHO, G.; JOBERT, A.; DEHAENE-LAMBERTZ, G.; KOLINSKY, R.; MORAIS, J.; COHEN, L. How Learning to Read Changes the Cortical Networks for Vision and Language. Science, n. 330, p.1359-1364, 2010.

DEHAENE, S. Os neurônios da leitura: como a ciência explica nossa capacidade de ler. Tradução de Leonor Scliar-Cabral. Porto Alegre: Penso, 2012. 372p.

Consciousness and the brain: deciphering how the brain codes our thoughts. New York: Viking, 2014. 336p.

DEHAENE, S.; COHEN, L.; MORAIS, J.; KOLINSKY, R. Illiterate to literate: behavioral and cerebral changes induced by reading acquisition. Nature Reviews Neuroscience, n. 16, p. 234-244, 2015.

FÁVERO, L. L.; KOCH, I. G. V. Critérios de textualidade. Veredas, v. 104, p. 17-34, 1985.

FLÔRES, O. C.; GABRIEL, R. O quebra-cabeça da leitura: leitor, texto, autor. In: MOURA, H.; GABRIEL, R. (Org.). Cognição na linguagem. Florianópolis: Insular, 2012. p. 219-236.

FRITH, U. Beneath the surfasse of developmental dyslexia. Surface dyslexia, v. 32, p. 301-330, 1985.

GABRIEL, R. A aquisição das construções passivas em português e inglês: um estudo translinguístico. Tese (Doutorado em Letras) - Programa de Pós-Graduação em Letras, Pontifícia Universidade Católica do Rio Grande do Sul, Porto Alegre, 2001.

GABRIEL, R.; FLÔRES, O. C.; SCHERER, L. C.; MOLINA, J. A. Aquisição e construção do sentido metafórico. Veredas, v. 15, n. 2, p. 107-115, 2011.

GABRIEL, R.; FLÔRES, O. C.; SCHERER, L. C. Reading comprehension performance according to age and education level. In: MININNI, G.; MANUTI, A. Applied Psycholinguistic: positive effects and ethical perspectives. Milano: Franco Angeli, v. I, 2012. p. 323-333.

GABRIEL, R.; MORAIS, J. ; KOLINSKY, R. A aprendizagem da leitura e suas implicações sobre a memória e a cognição. Ilha do Desterro, UFSC, v. 69, n.1, p. 61-78, 2016.

GABRIEL, R.; MORAIS, J. A leitura compartilhada, na família e na escola. In: FLÔRES, O. C.; GABRIEL, R. O que precisamos saber sobre leitura? Contribuições interdisciplinares. Santa Maria: Editora UFSM (no prelo).

GIBBS, R. W. The poetics of mind: figurative thought, language, and understanding. New York: Cambridge University Press, 1994.

GOUGH, P. B.; HILLINGER, M. L. Learning to read: an unnatural act. Bulletin of The Orton Society, v. 30, p. 179-195, 1980.

HOOVER, W. A.; GOUGH, P. B. The simple view of reading. Reading and writing: an interdisciplinar journal, v. 2, p. 127-160, 1990.

JOHANSSON, V. Lexical diversity and lexical density in speech and writing: a developmental perspective. Working Papers, v. 53, p. 61-79, 2008.

KAMHI, A. Knowledge deficits: the true crisis in education. The ASHA Leader, v. 12, n. 7, p. 28-29, 2007.

The case for the narrow view of reading. Language, Speech, and Hearing Services in Schools, v. 40, p. 174-177, 2009a.

Solving the reading crisis - Take 2: the case for differentiated assessment. Language, Speech, and Hearing Services in Schools, v. 40, p. 212-215, $2009 \mathrm{~b}$. 
KATO, M. No mundo da escrita: uma perspectiva psicolinguística. São Paulo: Ática, 1986. 144p. KINTSCH, W. Comprehension: a paradigm for cognition. Cambridge, UK: Cambridge University Press, 1998. 480p.

KOCH, I. V.; ELIAS, V. M. Ler e compreender: os sentidos do texto. São Paulo: Contexto, 2006. 216p.

KOCH, I. G. V. ; TRAVAGLIA, L. C. Texto e coerência. São Paulo: Cortez, 1989. 107p.

LAKOFF, G.; JOHNSON, M. Metaphors we live by. Chicago: Univ. Chicago Press, 2002. 256p.

LOPES, M. I. O impacto do "Pacto Nacional pela Alfabetização na Idade Certa" no ensino da leitura inicial em escolas municipais e estaduais de Santa Cruz do Sul: dando voz aos professores. 2015. Dissertação (Mestrado em Letras) - Programa de Pós-Graduação em Letras, Universidade de Santa Cruz do Sul, Santa Cruz do Sul, 2015.

MACWHINNEY, B.; BATES, E. The cross linguistic study of sentence processing. Cambridge: Cambridge University Press, 1989. 505p.

MARCUSCHI, L. A. Da fala para a escrita: atividades de retextualização. São Paulo: Cortez, 2007. 136p.

MORAIS, J. A arte de ler. Tradução de Álvaro Lorencini. São Paulo: Ed. UNESP, 1996. 327p.

Criar leitores: para professores e educadores. São Paulo: Manole. 2013. 154p.

Lire, écrire et être libre: de l'alphabetisation à la démocratie. Paris: Odile Jacob, 2016. 326p.

MORATO, E. M.; BENTES, A. B. Frames em jogo na construção discursiva e interativa da referência. Cadernos de Estudos Linguísticos, v. 55, n. 1, 2013.

NABOKOV, V. Pale fire. London: Penguin Books, 2011.310p.

NAGY, W. E.; ANDERSON, R. C. How many words are there in printed English? Reading Research Quarterly, v. 19, p. 304-330, 1984.

NATION, K.; COCKSEY, J.; TAYLOR, JO S.H.; BISHOP, D. V.M. A longitudinal investigation of early reading and language skills in children with poor reading comprehension. Journal of Child Psychology and Psychiatry, v. 51, n. 9, p. 1031-1039, 2010.

OCDE/INEP. Relatório Nacional PISA 2012: resultados brasileiros. Brasília: Fundação Santillana, 2013. Disponível em $<$ http://portal.inep.gov.br/pisa-programa-internacional-de-avaliacao-de-alunos $>$. Acesso em: 7 nov. 2014.

OCDE. 2012. PISA 2012 - Programm for International Student Assessment. Country note: Brazil. Disponível em $<$ http://portal.inep.gov.br/pisa-programa-internacional-de-avaliacao-de-alunos $>$. Acesso em: 7 nov. 2014.

PEGADO, F.; BRAGA, L. W.; NUNES FILHO, G.; JOBERT, A.; COHEN, L.; NAKAMURA, K.; VENTURA, P.; PALLIER, C.; MORAIS, J.; KOLINSKY, R. Literacy Breaks Mirror Invariance for Visual Stimuli: A Behavioral Study With Adult Illiterates. Journal of Experimental Psychology, v. 143, n. 2, p. 887-894, 2014.

SARAMAGO, J. Ensaio sobre a cegueira. São Paulo: Companhia das Letras, 1995. 312p.

SCHOTTER, E.; RAYNER, K. The Work of the Eyes During Reading. In: POLLATSEK, A.; TREIMAN, R. The Oxford Handbook of Reading. Oxford: Oxford University Press, 2015. p. 44-59.

SEIDENBERG, M. S. The science of reading and its educational implications. Language Learning and Development, v. 9, p. 331-360, 2013.

SNOWLING, M. J.; HULME, C. Annual Research Review: The nature and classification of reading disorders - a commentary on proposals for DSM-5. The Journal of Child Psychologyand Psychiatry, v. 53, n. 5, p. 593-607, 2012.

SOARES, M. Letramento e alfabetização: as muitas facetas. Revista Brasileira de Educação, v. 25, p. 517, 2004.

TOMASELLO, M. The cultural origins of human cognition. Cambridge: Harvard University Press, 1999. $248 \mathrm{p}$.

USA. Department of Education, Office of Elementary and Secondary Education. No child left behind: a desktop reference. Washington, DC, 2001. Disponível em

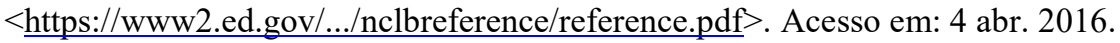

GABRIEL, Rosângela. Como o milagre da leitura é possível? Investigando processos biológicos e culturais da emergência de sentidos durante a leitura. Linguagem em (Dis)curso - LemD, Tubarão, SC, v. 16, n. 3, p. 603 616, set./dez. 2016. 
VYGOTSKY, L. S. Pensamento e linguagem. 2. ed. São Paulo: Martins Fontes, 1998. 194p.

ZIEGLER, J. C.; GOSWAMI, U. Reading acquisition, developmental dyslexia, and skilled reading across languages: a psycholinguistic grain size theory. Psychological Bulletin, v. 131, n. 1, p. 3-29, 2005.

ZIEGLER, J. C.; GOSWAMI, U. Becoming literate in different languages: similar problems, different solutions. Developmental Science, v. 9, n. 5, p. 429-453, 2006.

ZILBERMAN, R. Estética da recepção e história da literatura. São Paulo: Ática, 1989. 124p. Fim do livro, fim dos leitores? São Paulo: SENAC, 2001. 131p.

\title{
Recebido em: 04/07/16. Aprovado em: 21/07/16.
}

Title: How is the miracle of reading possible? Investigating biological and cultural processes of emergent meaning while reading

\begin{abstract}
Author: Rosângela Gabriel
Abstract: If in one hand reading is a particular use of language, on the other, in order to understand the cognitive aspects of reading, it is necessary to avoid extending inadvertently the field of application of this object of study (MORAIS, 1996). While investigating reading, it is necessary to investigate which cognitive and social aspects are specific to it, and which are shared with oral verbal language, or yet with other languages, taking into account processes of verbal and non-verbal meaning production. In this article, the elements strictly related to the acquisition and process of reading are disentangle from the ones that are shared with other language, especially with the oral language, seeking at identifying the conscious and unconscious processes involved (DEHAENE, 2012; 2014). An accurate definition of reading is necessary to support public policies and pedagogical intervention based on the state of art of the studies on language, reading and cognition.
\end{abstract}

Keywords: Reading. Learning. Processing. Conscious and unconscious process. Education.

Título: ¿Cómo el milagro de la lectura es posible? Investigando procesos biológicos y culturales de la emergencia de sentidos durante la lectura

Autora: Rosângela Gabriel

Resumen: Por una parte, si la lectura es una forma particular de usar el lenguaje verbal, por otra, para comprender los aspectos cognitivos involucrados en la lectura, é necesario evitar ampliar por inadvertencia el campo de aplicación de este objeto de estudio (MORAIS, 1996). Cuando investigando la lectura, cumple examinar que aspectos cognitivos y sociales con especificos a ella y que aspectos son compartidos con la modalidad oral, o aún con los demás lenguaje, considerando procesos de significación verbal y no verbal. Este artículo distingue elementos que son intrínsecos al aprendizaje y procesamiento de la lectura, y aspectos que son compartidos con los demás lenguajes, en especial con el lenguaje oral, buscando identificar procesos conscientes e inconscientes involucrados (DEHAENE, 2012; 2014). Una definición de lectura y la explicitación de su modo de procesamiento son necesarias para subsidiar el planeamiento de políticas públicas y acciones pedagógicas que estén ancladas en los avances de los estudios neurocientificos sobre lenguaje, lectura y cognición.

Palabras-clave: Lectura. Aprendizaje. Procesamiento. Proceso consciente e inconsciente. Educación.

Este texto está licenciado com uma Licença Creative Commons Atribuição 4.0 Internacional.

GABRIEL, Rosângela. Como o milagre da leitura é possível? Investigando processos biológicos e culturais da emergência de sentidos durante a leitura. Linguagem em (Dis)curso - LemD, Tubarão, SC, v. 16, n. 3, p. 603 616, set./dez. 2016. 